\title{
Using the ADAPT Strategy to Facilitate the Thinking Process of Creating Universal Design Based Instructional Adaptions and Differentiation in Lesson Plans for Diverse Learners
}

\author{
Michelle Chamblin \\ Molloy College Kellenberg Building, Rockville Centre, NY, USA \\ Email:mchamblin@molloy.edu
}

How to cite this paper: Chamblin, $M$. (2017) Using the ADAPT Strategy to Facilitate the Thinking Process of Creating Universal Design Based Instructional Adaptions and Differentiation in Lesson Plans for Diverse Learners. Open Access Library Journal, 4: e3585.

https://doi.org/10.4236/oalib.1103585

Received: April 7, 2017

Accepted: May 13, 2017

Published: May 16, 2017

Copyright (c) 2017 by author and Open Access Library Inc.

This work is licensed under the Creative Commons Attribution International License (CC BY 4.0).

http://creativecommons.org/licenses/by/4.0/

\begin{abstract}
The effects of a learning strategy to prompt deeper thinking and the incorporation of more UDL instructional differentiations and adaptions in the lesson plans by pre service and early career teachers were examined. Class 1 (control) received a 2.5 hour lecture with guided practice about Universal Design for Learning. Class 2 (experimental) received a 2.5 lecture with guided practice about Universal Design for Learning with the ADAPT Strategy incorporated. A modeled thinking process of the ADAPT strategy was provided. The participants' $(n=43)$ application of Universal Design strategies to adapt lesson plans for diverse learners was compared using a rubric. Three lesson plans for each participant was collected for both Class 1 and Class 2. The first lesson plan was collected in the beginning of the course prior to instruction; the second, after the 2.5 lecture with guided practice for Class 1 (control) and the UDL training with the ADAPT strategy for Class 2 (experimental). The third lesson plan was collected four weeks after for both Class 1 and 2 as a second posttest. Class 2 (experimental) employed more UDL strategies and scored significantly higher than Class 1 (control) on the second and final lesson plan. Moreover, Class 2 participants had adaptions which were well connected to the lesson, evidenced by explicit explanations of where, when and why the adaption would be used. Additionally, more evidences of tying the lesson to the learners in the case study were noted. The results suggest that experience in thinking about "how" to create adaptions may be a necessary opportunity required by pre-service and early career teachers to practice differentiating instruction and making adaptation.
\end{abstract}

\section{Subject Areas}

Education 


\section{Keywords}

Special Education, Students with Disabilities, Adaptions, Modifications, Instructional Strategies, Inclusion, Learning Strategies, General

Education, Teacher Learning, Universal Design for Learning, Lesson Plans

\section{Introduction}

Adapting instruction is the hallmark of effective instruction and visceral for students with disabilities who are in inclusive settings (Janney \& Snell 2000 [1]; Breitfelder 2008 [2]; National Center for Children with Disabilities [3]). Without effective adaptions, students with disabilities are not able to access the curriculum, the learning targets or the knowledge they will need to be informed citizens (Fuchs, Fuchs, Hamlett, Phillips and Karns 1995 [4]). As the number of students with disabilities increases in inclusive settings, their representation in high stakes assessments used to inform educational practices is also on the rise (National Council on Disability [5]; National Center for Education Statistics [6]). These students and their families are major stake holders in a system which is addressing their education needs in the least restrictive environment. This shift in paradigm is quite different from the historical perspective in which students with special needs were taught mostly in segregated classrooms, only exposed to specialized curriculum and not an integral part of the school culture (Lee, Amos, Gragoudas, Lee, Shogren, Theoharis and Wehmeyer 2006 [7]). Now that there is a push towards inclusion, all teachers need to know how to adapt instruction for students with disabilities. Moreover, they need to know how to make adaptions that matter which are instructional adaptions that are meaningful and support the learner in the general education curriculum.

Yet research shows that pre-service and novice teachers are not fully developed in this area (Ko 2012 [8]; Beyer and Davis 2009 [9]; Chesley and Jordan 2012 [10]; Dee 2011 [11]). These teachers tend to develop adaptions which are disconnected to the lesson, not implemented with ease and teachers couldn't connect the adaption to the student's needs or Individual Education Program Goals (Kurth and Keegan 2012 [12]). In some of these same studies, authors concluded that veteran teachers provided adaptions that were effective and from their experiences they had learned how to make these adaptions. Learning how to make effective adaptions was not a result of their pre-service education (Scott, Vitale \& Masten 1998 [13]). This raises the question of how pre-service teachers are prepared to create adaptions in their pre-service training.

\section{Purpose of Study}

\subsection{More Focus on How Rather Than What}

With a wealth of information concerning students with disabilities, why is it that pre-service and early career teachers are not developed in this area? There is a 
wealth of information concerning making adaptions for students with disabilities. However, this information is mostly concerned with what an adaption can be but not how to make an adaption (Salend 2005 [14]). The lack of representation in the research as to how teachers move through a lesson and make decisions, may speak to the issue. It is easy to list what an adaption should be, for example, enlarging print or allowing for extra time to process information, however, it is more difficult to explain how to go through a lesson step by step to find those areas which need to be adapted, where to implement the adaption and steps for evaluating the effectiveness of the adaption. For experienced teachers, this process becomes precise as a result of practice and the necessity to adapt for students daily. Yet, the pre-service and novice teacher also needs to learn this process and it is hypothesized in this paper that the modeling of this thinking can be reduced into a strategy, so that this process is teachable.

\subsection{Background Arguments Supporting the Need for "How"}

There is a plethora of information that explore what (Schiering, Bogner, and $\mathrm{Bu}-$ li-Holmberg 2011 [15]) an adaption is and lists that suggest what you can do for students, by disability category. However, there is a lack on how to make an instructional adaption. In other words, there is a need to explain and model the thinking process of how to engage in the making of instructional adaption for students with disabilities and incorporating those adaptions into the lesson. By learning how to engage in this process, teachers can adopt this practice which will aid in the development of adaptions that are relevant, enhance student learning outcomes and maintain student engagement in instruction.

To further illustrate this point, if one was to search adaptions for students with Emotional Behavioral disorders (ED), you may find suggestions such as the following found at A Child with Needs [16]:

- Set up goals that increase at social interactions

- Use role-playing situations in instruction

- Create seating arrangements to encourage social interaction.

- Include students with EBD in the planning process of the IEP.

- Discuss I.E.P. goals with the student

- Set up personalized goals and strategies

- Children with Emotional Behavior Disorders may present extra challenges to his/her caregiver in forms of outbursts and disobedience. The caregiver cannot give into this as it only validates the child's behavior. Instead caregiver needs to challenge students to keep them learning new skills

These are just a few of the many suggestion of what can be done but understanding how to incorporate this into instruction is a more involved process.

This can also be the case for Learning Disabilities and many students with disability receive their education in inclusive settings. The novice teacher will find many suggestions of what he can do, for example, the National Center for Learning Disabilities [17] recommends the following which is found on their website:

- Presentation: 
- Reduce number of items per page or line

- Provide a designated reader

- Present instructions orally

- Response:

- Allow for verbal responses

- Allow for answers to be dictated to a scribe

- Allow the use of a tape recorder to capture responses

- Permit responses to be given via computer

- Permit answers to be recorded directly into test booklet

- Timing:

- Allow frequent breaks

$\circ$ Extend allotted time for a test

- Setting:

- Provide preferential seating

- Provide special lighting or acoustics

- Provide a space with minimal distractions

- Administer a test in small group setting

- Administer a test in private room or alternative test site

- Test Scheduling

- Administer a test in several timed sessions or over several days

- Allow subtests to be taken in a different order

- Administer a test at a specific time of day

- Other

- Provide special test preparation

- Provide on-task/focusing prompts

- Provide any reasonable accommodation that a student needs that does not fit under the existing categories

All of these are excellent suggestions but that is exactly what they are, suggestions. Understanding how to take this information and apply it to a learner and lesson is the how of making an instructional adaptation. Novice teachers may need more direction and assistance on the how of planning instructional adaptions in a step by step formulaic way to learn this process until they develop their own method of expertise which they will gain from teaching experiences.

Some articles have approached this issue by modeling the thinking of teachers when they make instructional adaptions (Udvari-Solner 1996 [18]; Kurth 2013 [19]; Ornstein 1997 [20]). Having a thinking model or reflective process may give the novice teacher a model for how to plan instructional adaptions, organizing and orchestrating best practices into their instruction.

\section{Research Background}

A lesson plan format can be used to help teachers plan the segments of instruction while a comprehensive framework such as Universal Design for Learning can help teachers think about making the learning segments accessible for all 
learners. A learning strategy can be used in conjunction with the lesson plan and Universal Design for learning concepts to help the teacher think through the process of how to think, reflect and execute.

\subsection{Learning Strategies}

Learning strategies are used to ignite metacognition. Research in this area has shown that learning strategies are effective in helping subjects think through tasks. Effective learning strategies help in the planning, execution and evaluation of mental tasks, guiding the individual to focus more about the "how" of learning, opposed to the "what". For example, this can be done by creating a mnemonic device, encapsulated in a word that is easy to remember. Each step of the device is brief and details some overt action in a systematic way which includes planning, acting and reflecting (Dreshler, Ellis, Lenz 1996 [21]; Bulgren, Schumaker \& Dreshler 1994 [22]; Dreshler \& Shumaker 1988 [23]; Hock, Dreshler \& Shumaker 1993 [24] Chamblin 2017 [25]). Learning strategies are designed so that the learner can think through acronyms can also be effective learning strategies. For example the acronym "Flexible" was created by Shumm 1999 [26] to think about the characteristics of adaptations in elementary school in the areas of reading and math. Principle questions are asked and reflected upon as the teacher sets forth to adapt materials. This learning strategy facilitates deeper thinking of the teacher by requiring time on how before jumping into the what of an adaption.

Flexible

1) Feasible: Is the adaption feasible for classroom teachers to implement?

2) Lively: Is the adaption lively, engaging, and/or fun?

3) Eliminated: Is the adaption set up so that it can be gradually faded?

4) Explicit: What area/skill deficit does this adaption specifically address?

5) Intentional: Is the adaption a part of a comprehensive plan for the student with disabilities?

6) Beneficial: Will the adaption benefit the student with disabilities?

7) Limelight: Does the adaption place undue attention on the student with disabilities or put the student in a potentially embarrassing situation?

8) Evaluated: How will I evaluate the adaption on an ongoing basis?

\subsection{The ADAPT Strategy}

Based within the learning strategies approach, the ADAPT strategy (Chamblin, 2014 [27]) was created to help pre-service and early career teachers who struggled with the concept of making adaptions and differentiating instruction. More specifically, pre-service and in-service teacher were unable to process how to make adaptions for students with exceptionalities that were meaningful, purposeful and useful. The goal of the ADAPT strategy is to assist teachers in the thinking process as they reflect on the nut and bolts of a pre-planned lesson and then go back with the learners in mind and make the appropriate adaptations. This process calls for the teacher to first plan instruction which is aligned to 
standards and had an objective, motivation, materials, procedure, strategies, assessment and independent practice. The reason for this is that pre-service teachers and early career teachers need to first have a lesson with the basic information. They need to know what they intend to teach. Secondly they must think about diverse learners in general, however, to learn how to adapt instruction it is important to have a case study or actual profile of learners. Reflecting on the lesson and learners, the teachers can then go through the parts of the lesson and determine what needs to be addressed. This process is detailed in Appendix A.

\subsection{Universal Design}

Of the many theories of how to eliminate barriers in a lesson and facilitate how to incorporate adaptions, Universal Design for learning is the most comprehensive and more current framework (Rose \& Meyer 2002 [28]). Universal Design originated in the field of architecture with the concept that buildings, products and environments should be accessible for all people with a wide range of physical and cognitive abilities. If these items are design well, first, then the process of revisiting these items to change them is reduced significantly (Rose et al. 2006 [29]). This concept was applied to the field of education by CAST, The Center for Universal Design at North Carolina State University. CAST has developed a UDL framework which emphasizes that curriculum and teaching be flexible and address the needs of diverse students in the planning phase. In addition CAST recommends that teachers reflect upon their lesson plans and curriculum to determine if they are inclusive (CAST, 2011 [30]).

In the Guideline document produced by CAST, there are three categories for consideration. The teacher should consider how the content of the lesson is represented. The teacher should consider the process of how information is delivered in the lesson. The teacher should consider the product which will be a result or evidence of student learning, and determine if all of these are designed for the diversity of learners to be educated.

These three considerations are embedded in the three main principles of UDL. The first is to present information in multiple formats so that all students can access it. The second principle is to allow students alternative ways to express or demonstrate what they have learned and the third principle is to stimulate the student's interest and motivation for learning in a variety ways so that the student is engaged (CAST, 2015 [31]).

This neuroscience approach taps into the Recognition Network, the Strategic Network and the Affective Network which are articulated in the three principles:

1) Provide Multiple Means of Representation

2) Provide Multiple Means of Action Expression

3) Provide Multiple Means of Engagement

These three principles are further reduced to nine guideline and 31 checkpoints. The UDL Educator's Guide which can be found on the CAST website details each checkpoint and provides many examples in Appendix B.

The concept of UDL has been implemented and tested in education and lesson planning with many promising results. Azawei et al. (20016) [32] conducted 
a content analysis of peer-reviewed papers and found 12 studies that fit the criteria for analysis. His findings concluded that the benefits of using UDL in education and lesson planning included: minimizing learning barriers, the creation of inclusive curriculums, improvements in learner's self-perceptions and providing teacher's with opportunities to expand their understanding to design more accessible lessons.

\subsection{Universal Design and Lesson Planning}

Spooner et al. examined the effects of UDL training in lesson plan development in 2007 [33]. In this study students were randomly assigned to either a treatment group or control group. A pretest/posttest design. Using a three leveled rubric designed by the researchers, the student's pretest lesson plan was scored. The treatment group was afforded the intervention which was a 1-hour lecture on how to modify lessons for a student with either a mild or severe disabilities using the three components of UDL. The control group did not receive the lecture. During the posttest the students' lesson plan was evaluated using the rubric. It was concluded that the training in UDL enabled the intervention group to develop lesson plans that included the student. The intervention group also demonstrated more growth between the pretest and posttest rubric score.

With some changes, Courey et al. [34] replicated some components of this study in 2012 to examine the effects of UDL training in improved lesson planning. Students studying to become Special Education Teachers in Inclusive setting were used as subjects. Researchers wanted to determine if UDL training would impact the students' use of the principles in lesson planning for diverse students and if the acquired knowledge would be generalized to their lesson planning repertoire. In addition they investigate how the students would use the UDL principles in conjunction with state standards. Students wrote a lesson plan before training. All students experienced the intervention which was a 3-hour UDL training. Students wrote and submitted a lesson plan immediately after training and once again at the end of the semester. The lesson plans during the three phases were evaluated based on the rubric created by Spooner (Appendix C). The results determined that the 3-hour training was effective in the students incorporating all three principles of UDL in the lesson plan with a larger effect between the first and second lesson plan. Researchers also noted that although there was improvement, items on the lesson plan mentioned in "Materials" was not used in the lesson plan. Also some of the incorporated activities may be cumbersome and researchers questioned whether the adaptions mentioned could be used in a real classroom. Researchers concluded that UDL concepts in lesson planning need to be refined in preparation and practice.

\section{Method}

\subsection{Participants}

The participants were 43 graduate students pursuing special education certification but had certification or pursuing certification in a content area such as 
Math, English, Social Studies, Childhood 1 - 6 or Science. Participants were enrolled in one of two sections of a special education course taught by the author. The participants ranged in age from 21 to 32 with a mean age of 25.3 and were $97 \%$ female. The ethnicities of these participants were $1 \%$ African American, $1 \%$ Hispanic and $98 \%$ Caucasian. The teaching experience ranged with $24 \%$ being full time classroom teachers for two years in a public or private school, $32 \%$ full time classroom teachers in their first year of teaching in a public or private school, $10 \%$ substitute teachers for two years in a public or private school, $11 \%$ working as teacher's assistants in a public or private school, $10 \%$ working in day care settings and $13 \%$ working in an field outside of education.

\subsection{Setting}

All participants gave consent and allowed the researcher to use their three lesson plans for this project. The lessons plans were a normal requirement of the course. Participants who would have refused participation in the study would have resulted in not using their lesson plan for the analysis. However, all participants agreed and there was $100 \%$ participation. The two sections of similar courses were used. Both courses include UDL strategies in the course outline.

\subsection{Procedure}

\subsubsection{Pre-Test-Lesson Plan 1}

In both courses, participants were asked to submit a benchmark lesson plan at the beginning of the semester from course (ABC).

The Division of Education at this setting utilizes a standardized lesson plan template. As an existing policy and practice, students in the Division of Education at this setting, are instructed on lesson planning techniques in various courses and workshops using this template. Student exposure to the template varies but for the participants of this study, all had used the template for two or more courses preceding this study. The section Differentiation of Instruction and Adaptations appears on the template and this was the area of focus. Students in the Division of Education, including the participants of this study, have been directed by to differentiate and adapt for all lessons. They have been exposed to a variety of methods and approaches but up to this point in the sequence of courses, no in-depth UDL training occurs.

Course $(\mathrm{ABC})$ was selected because it is not a special education course; does not provide UDL training; the participants for this study took the course in the semester preceding the study with the same instructor and were required to write lesson plans for diverse learners using the standardized lesson plan template.

\subsubsection{Intervention-Lesson Plan 2}

During Session 4, Class 1 received UDL training in form of a class lecture. The CAST website was used. The Guidelines were covered and students were given the Educator's Worksheet (Appendix A). Participants were also allowed to use computers in class because the online version of the Educator's Worksheet fur- 
ther explains each check point. Participants were given a case study and a mock lesson plan which utilized the standardized lesson plan template used by the Division of Education. In small groups, participants were guided to discuss the differentiation and adaptions that were created in the mock lesson plan, consider the UDL training and decide if the lesson plan addressed the needs of the students in the case study class. The small group discussions were shared. Participants were then given another partial lesson plan in the form of the standardized lesson plan used in the Division of Education. The Differentiation of Instruction and Adaptions sections were missing. Participants were asked to write and submit how they would differentiate for the students in the case study class and how they would adapt instruction for exceptional students mentioned in the case study class. The participants' responses were handed in at the end of the session.

For Session 4, Class 2 also experienced the same UDL lecture. After the lecture, the participants received the same case study class and mock lesson plan as Class1. However, Class 2 was given the ADAPT strategy and the researcher explained the strategy and modeled the thinking process of going through the lesson, the UDL check points and case study class information.

After the ADAPT strategy presentations, participants were then given another partial lesson plan from the same standardized lesson plan used in the Division of Education. The Differentiation of Instruction and Adaptions sections were missing. Participants were asked to write and submit how they would differentiate for the students in the case study class and how they would adapt instruction for exceptional students mentioned in the case study class. The participants' responses were handed in at the end of the session.

\subsubsection{Posttest-Lesson Plan 3}

During Session 10, Class 1 was given the same case study class and partial lesson plan. Participants were then asked to write the Differentiation of Instruction and Adaptions section of the lesson plan. This was submitted. The Intervention/ ADAPT strategy was presented after the collection of the post test.

During Session 10, Class 2 was given the same case study class and partial lesson plan. Participants were also asked to write the Differentiation of Instruction and Adaptions section of the lesson plan. This was submitted. Class 2 moved on to the next topic in the syllabus after the post test.

\subsection{Instrumentation}

As mentioned, the standardized lesson plan template section of Differentiated Instruction and Adaptions were of focus. In this section of the template, participants addressed the totality of the plan and how to make the lesson accessible for all learners. Participants were taught that on the standardized lesson plan the Differentiation of Instruction section speaks to the entire class whereas the Adaption section is reserved to detail how you would adapt the lesson for students who are exceptional including but not limited to students with disabilities, and English as a New Language students (ENL). Participants were asked to address these two sections of the lesson plan for this study. 
These sections were graded on a 3-point scale designed by Spooner et al. (2007) and later used by Courey et al. (2012). The rubric assesses the presence of 1) multiple means of representation, under the label, representation; 2) multiple means of expression, under the label, expression and 3) multiple means of engagement, under the label, engagement.

If these are no presence of these elements the score is zero. If there are one or two elements the score is one point and three or more resulting in 2 points.

\section{Results and Conclusions}

This study investigates if a learning strategy focusing on how to think about adaptions in the UDL framework would improve the participants of addressing these elements in lesson planning. Although both classes were provided with UDL training the intervention group was given the ADAPT strategy and the thinking model of planning, acting and reflecting was modeled by the researcher. Three lesson plans were submitted and scored with a UDL rubric. The means of each class aggregated by representation, expression and engagement are reported in Table 1.

Just to note that the scoring rubric focuses on engagement of students with disabilities, however, in scoring for this study engagement was scored for at the 0,1 and 2 point level for strategies which engaged students with and without disabilities in the case study class that needed that support.

Comparing the means of Class 1 and Class 2, it is evident that Class 2 earned higher scores on the rubric. This is true for the pre-test phase as well. Lesson 2 during the intervention, both groups had increased scores, however, the difference in mean scores between Class 1 and Class 2 are greater proportionally than between the mean scores than during the pretest phase. Although both Classes improved, Class 2 improved to a greater degree. To further determine if there were significant differences between the means, a t-test was used.

For lesson 1 there was a statistical difference in all three categories with a $\mathrm{p}<$ 0.05. The same was true for Lesson 2. For Representation there was a statistical difference in Class $1(\mathrm{M}=0.45, \mathrm{SD}=0.85)$ and Class $2(\mathrm{M} 1.57, \mathrm{SD}=0.69)$ conditions; $\mathrm{t}(41)=-6.7 \mathrm{p}=0.000$. For Expression there was a statistical difference in Class $1(\mathrm{M}=0.90, \mathrm{SD}=0.70)$ and Class $2(\mathrm{M} 1.45, \mathrm{SD}=0.69)$ conditions; $\mathrm{t}(33)=-2.7 \mathrm{p}=0.001$. For Engagement there was a statistical difference in Class $1(\mathrm{M}=0.95, \mathrm{SD}=0.71)$ and Class $2(\mathrm{M} 1.87, \mathrm{SD}=0.69)$ conditions; $\mathrm{t}(41)=-4.5$

Table 1. Means of Class 1 and Class 2 for Lesson Plan 1.

\begin{tabular}{cccccccccc}
\hline & \multicolumn{3}{c}{ Lesson 1 } & \multicolumn{3}{c}{ Lesson 2 } & \multicolumn{3}{c}{ Lesson 3 } \\
\cline { 2 - 9 } & Rep. 1 & Ex.1 & En. 1 & Rep. 2 & Ex. 2 & En. 2 & Rep. 3 & Ex. 3 & En. 3 \\
\hline Class 1 & 0.30 & 0.85 & 0.71 & 0.45 & 0.90 & 0.85 & 0.95 & 1.65 & 1.65 \\
Class 2 & 1.26 & 1.39 & 1.09 & 1.57 & 1.45 & 1.59 & 1.85 & 1.91 & 1.89 \\
\hline
\end{tabular}

The means scores of the presences of Multiple Means of Representation (Rep), Multiple means of Expression (Ex) and Multiple Means of Engagement (En) in Lesson plans 1, 2 and 3 for Class 1 and Class 2. 
$\mathrm{p}=0.000$. Lesson 3 demonstrated no statistical differences in the means. A summary significance can be found in Table 2 .

It can be concluded that the significant differences in the means for lesson 1 were attributed to factors and variables outside the scope of this study. It was expected that the students in Class 1 and Class 2 would not have a statistical difference in the means at the pretest phase. No statistical differences would indicate that students were at the same level in the beginning of the study. However, Class 2 could be described as an academically stronger group although class composition is random. It can be concluded that Class 2, had a better grasps and understanding of lesson planning, differentiation of instruction and making adaptions from the onset.

It was expected that there would be a statistical difference for lesson plan 2 . There was and this supports the descriptive analysis. It was apparent that Class 2 included more adaptions in the materials, methods of communication and engagement strategies when compared to Class 1 . Class 2 without request, indicated in their differentiation of instruction and adaptions for the students in the case study indicated where and why as they described their adaptions and differentiations for expression and engagement. For example a student noted that during the lesson plan procedure there was a transition in which the students needed to move from centers to full group instruction. Multiple strategies were suggested and it was noted where in transition and why this particular transition would be difficult for the student in the case study.

Class 2 wrote their adaptions in a narrative style, somewhat more as a conversation addressing the students in the case study as though they had met them. Whereas, Class 1 used bulleted form, citing directly from the Educator's Worksheet and providing an example, website or name of a strategy. It seemed that Class 2 simulated the classroom experience and focused more on the student in the case study that had the most needs. Although Class 2 scored higher on the rubric for Lesson 3, there were no significant differences between groups. Within groups, Class 1 made more gains.

\section{Limitations}

The results of this study indicate that using a learning strategy such as ADAPT can help in the creation better quality adaptions for diverse learners. The strategy takes time and has many steps. In order for this to generalize, the participant

Table 2. Significant Differences in Means for Class 1 and Class 2 across Lesson Plan 1, 2 and 3.

\begin{tabular}{cccc}
\hline & Representation & Expression & Engagement \\
\hline Lesson 1 & Significant Difference & Significant Difference & Significant Difference \\
Lesson 2 & Significant Difference & Significant Difference & Significant Difference \\
& & & No Significant \\
Lesson 3 & No Significant Difference & No Significant Difference & Difference \\
\hline
\end{tabular}

The findings of significant difference of the means of scores or no significant means of scores for Multiple means of Representation, Multiple means of Expression and Multiple Means of Engagement for Lesson 1, 2 and 3 between Class 1 and Class 2 . 
would need to be dedicated to go through the steps often until mastery of the strategy.

Class composition in higher education has many variables and to compare two classes, there will most definitely be many which are out of the scope of the study which may impact the results. This was evident in the pretest differences. In addition the effects of the Adapt strategy could have been due to the strategy, the researcher's demonstration and modeling and/ or the questions that were answered about using UDL which were spontaneously asked and answered during the intervention. It is difficult to separate this and this was not considered when planning the research design.

This study took place at a small college in which student in the graduate program share information, discuss assignments and grades. Students in Class 1 and Class 2 were not directed to not discuss the contents of the course. Therefore it seems that Class 2 may have shared information about the ADAPT strategy with Class 1, possibly altering their expectations and knowledge about how to make adaptions. This may have influenced the results on lesson 3. Class 1 may have been exposed to the intervention before writing lesson plan 3 .

The UDL framework was designed to help all learners and when lessons are planned. There should be elements of all three principles presented in each lesson according to theory and the scoring rubric. UDL principles in this study were used to differentiate instruction and created adaptions to make the mock lessons accessible for learners in the case study. An unexpected outcome was that the participants focused in on the needs of the students in the case study and determine which parts of the lesson plan needed to be altered based on the needs as the priority and not having all the UDL principles represented. For example a lesson may not have had multiple representations but the participant felt that the expression and engagement of the lesson needed multiple elements and specially tailored elements for exceptional learners in the case study. The participant received a zero on the rubric for Representation. The shift in focus due the case study brought unintended and unplanned consequences that the researcher did not foresee. This can be evidenced in the procedures. The directions given to the participants by the researcher, in both Class 1 and Class 2 guides them to focus on the learners in the case study. This may have overshadowed the fact that UDL in general preplans for the students that you don't have should always include multiple means of representation, expression and expression in every lesson.

Additionally, due to the fact that both Class 1 and Class 2 were in special education course, participants tended to fall back on various methods previously learned to differentiate instruction prior to their special education training and focus primarily on adaptions for the students with exceptionalities in the case study. Although the various methods of differentiating instruction have UDL elements, it was evident that the adaptions contain more of those elements. It seems that the participants anticipated that the expectation for the special education course was to focus primarily on the special education students in the case 
study.

\section{Discussion}

In this study, the effect of the learning strategy ADAPT was tested to ascertain whether it would enhance the participants' ability to incorporate the principles of UDL in differentiating instruction and adapting instruction for diverse students. The results did demonstrate that there was a difference between the two group with the group receiving the intervention incorporating more ULD principles than the group that did not have the ADAPT strategy. However the group that had the intervention began the course with higher scores on the pretest lesson plan.

Modeling the ADAPT strategy may have also influenced the performance of Class 2. Demonstrating how K-12 teachers think through a problem and modelling it for students is a "best practice". In higher education this may not be the case, because the goal is for students to think for themselves and learn how to problem solve. Yet, the participants in this study commented that modeling the think and going through the steps with reflective questions was extremely useful. In addition during modeling of the ADAPT strategy the concept of where an adaption can occur became a focus. The intervention class saw modeling of adaptions in sections that are naturally linked. For example, if the adaption for expression occurred in the objective, the participants saw the thinking process concerning assessment and homework.

Differentiating instruction and making adaptions is a skill to be acquired. It takes time for pre-service teachers and early career teachers to acquire this skill but one way to help facilitate the process is by using UDL strategies in lesson planning. This process is monumental and taking the time to train teacher to think through the process is essential. Learning strategies such as the ADAPT strategy are simply but effective. Using the ADAPT strategy provides opportunities to reflect and organize the UDL principles, needs of the students and actions to be taken. This helps the individual "wrap her mind" around the concept and derive an internal metacognitive way to systemize the process. Honoring that how to think about this process and providing pre-service and early career teachers with opportunities to do so can only be beneficial.

\section{References}

[1] Janney, R. and Snell, M. (2000) Modifying Schoolwork in Inclusive Classrooms. Theory into Practice, 45, 215-223. https://doi.org/10.1207/s15430421tip4503_3

[2] Breitfelder, L. (2008) Quick and Easy Adaptations and Accommodations for Early Childhood Students. Teaching Exceptional Children Plus, 4, Article 2.

http://escholarship.bc.edu/education/teplus/vol4/iss5/art2

[3] National Center for Children with Disabilities. https://www.fhi360.org/projects/national-dissemination-center-children-disabilities -nichcy

[4] Fuch, L., Fuchs, D., Hamlett, C., Phillips, N. and Karns, K. (1995) General Educators' Specialized Adaption for Students with Learning Disabilities. Exceptional 
Children, 61, 440-459.

[5] National Council on Disability. http://www.allgov.com/departments/independent-agencies/national-council-on-dis ability?agencyid $=7335$

[6] National Center for Education Statistics. https://nces.ed.gov/

[7] Lee, S., Amos, B., Gragoudas, S., Lee, K., Shogren, K., Theoharis, R. and Wehmeyer, M. (2006) Curriculum Augmentation and Adaptation Strategies to Promote Access to the General Curriculum for Students with Intellectual and Developmental Disabilities. Education and Training in Developmental Disabilities, 41, 199-212.

[8] Ko, E. (2012) What Is Your Objective? Preservice Teachers' Views and Practices of Instructional Planning. The International Journal of Learning, 18, 89-100.

[9] Beyer, C. and Davis, E. (2009) Supporting Preservice Elementary Teachers' Critique and Adaptation of Science Lesson Plans Using Educative Curriculum Materials. Journal of Science Teacher Education, 20, 517-536. https://doi.org/10.1007/s10972-009-9148-5

[10] Chesley, G. and Jordan, J. (2012) What's Missing from Teacher Prep. Educational Leadership, 41-45.

[11] Dee, A.L. (2011) Preservice Teacher Application of Differentiated Instruction. The Teacher Educator, 46, 53-70. https://doi.org/10.1080/08878730.2010.529987

[12] Kurth, J. and Keegan, L. (2012) Development and Use of Curricular Adaptations for Students Receiving Special Education Services. The Journal of Special Education, 48, 191-203. https://doi.org/10.1177/0022466912464782

[13] Scott, B., Vitale, M. and Masten, M. (1998) Implementing Instructional Adaptations for Students with Disabilities in Inclusive Classrooms, a Literature Review. Remedial and Special Education, 18, 106-119. https://doi.org/10.1177/074193259801900205

[14] Salend, S.J. (2005) Creating Inclusive Classrooms: Effective and Reflective Practices for All Students. Prentice Hall, Upper Saddle River.

[15] Schiering, M.S., Bogner, D. and Buli-Holmberg, J. (2011) Teaching and Learning. Rowman and Littlefied, Lanham.

[16] A Child with Needs. http://www.achildwithneeds.com/disabilities/emotional-disability/emotional-behavi oral-disorder-accommodations-and-modifications/

[17] National Center on Learning Disabilities (n.d.) Accommodating Students with L.D. http://www.ldonline.org/article/8022

[18] Udvari-Solner, A. (1996) Examining Teacher Thinking, Constructing a Process to Design Curricular Adaptations. Remedial and Special Education, 17, 245-254. https://doi.org/10.1177/074193259601700407

[19] Kurth, J. (2013) A Unit-Based Approach to Adaptations in Inclusive Classrooms. Teaching Exceptional Children, 46, 34-43. https://doi.org/10.1177/004005991304600204

[20] Ornstein, A.C. (1997) How Teachers Plan Lessons. High School Journal, 80, 227237.

[21] Deshler, D., Ellis, E. and Lennz, B. (1996) Teaching Adolescents with Learning Disabilities. Love Publishing Co., Denver.

[22] Bulgren, J.A., Schumaker, J.B. and Dressler, D.D. (1995) Effectiveness of a Concept Teaching Routine in Enhancing the Performance of LD Students in Secondary-Level Mainstream Classes. Learning Disability Quarterly, 11, 3-17. https://doi.org/10.2307/1511034 
[23] Dreshler, D.D. and Schumaker, J.B. (1988) An Instructional Model for Teaching Students How to Learn. In: Graden, J.L., Zins, J.E. and Curtis, M.J., Eds., Alternative Educational Delivery Systems. Enhancing Instructional Options for All Students, NASP, Washington DC, 391-411.

[24] Hocks, M.F., Dreshler, D.D. and Schumaker, J.B. (1993) Learning Strategy Instruction for at Risk and Learning Disabled Adults: The Development of Strategic Learners through Apprenticeship. Preventing School Failure, 38, 43-49. https://doi.org/10.1080/1045988X.1993.9944294

[25] Chamblin, M. (2016) Seeing through a Different LENS: Can Applying a Learning Strategy Deepen self Reflection of Pre Service Teachers? Open Access Library Journal, 3.

[26] Shumm, J.S. (1999) Adapting Reading and Math Materials for the Inclusive Classroom. Volume 2: Kindergarten through Grade Five. ERIC/OSEP Mini-Library. ERIC Clearinghouse on Disabilities and Gifted Education, Reston. ERIC/OSEP Special Project on Interagency Information Dissemination; Council for Exceptional Children, Reston.

[27] Chamblin, M. (2014) The ADAPT Strategy: Thinking It through to Join the Lesson and the Learner. Unpublished Manuscript, Molloy College, Rockville Centre.

[28] Rose, D.H. and Meyer, A. (2002) Teaching Every Student in the Digital Age: Universal Design for Learning. Alexandria.

[29] Rose, D., Harbour, W., Johnston, C.S., Daley, S. and Abarbanell, L. (2006) Universal Design for Learning in Postsecondary Education. Journal of Postsecondary Education and Disability, 19, 17.

[30] CAST (2011) Universal Design for Learning (UDL) Guidelines Version 2.0. Author, Wakefeild.

[31] CAST (2015). http://www.cast.org/

[32] Al-Azawei, A., Serenelli, F. and Lundqvist, K. (2016) Universal Design for Learning (UDL): A Content Analysis of Peer-Reviewed Journal Papers from 2012 to 2015. Journal of the Scholarship of Teaching and Learning, 16, 39-56. https://doi.org/10.14434/josotl.v16i3.19295

[33] Spooner, F., Baker, J., Harris, A., Ahlgrim-Delzell, L. and Browder, D. (2007) Effects of Training in Universal Design for Learning on Lesson Plan Development. Remedial and Special Education, 28, 108-116. https://doi.org/10.1177/07419325070280020101

[34] Courey, S., Tappe, P., Siker, J. and Lepage, P. (2012) Improved Lesson Planning with Universal Design for Learning (UDL). Teacher Education and Special Education, 36, 7-27. https://doi.org/10.1177/0888406412446178 


\section{Appendix A}

\section{The ADAPT Strategy}

A analyze the student's needs, strengths and assets

D dig into the pre-planned lesson parts: objective, material, motivation, procedure, strategies, assessment, independent practice

A ask reflective questions concerning mis matches for the diverse learners after envisioning the pre-planned parts

Are there multiple means of representation for what is essential in this lesson?

Are there multiple ways for the student to express what he knows?

Are there several pathways or points to initiate and sustain engage-

ment?

$\mathbf{P} \quad$ put "it" in words and then in writing

T tessellate-does the adaption fit in the lesson without causing attention which is potentially embarrassing?

Note: The ADAPT Strategy developed by Chamblin, 2014

\section{Appendix B}

I. Provide Multiple Means of Representation:

1. Provide options for perception

1.1 Offer ways of customizing the display of information

1.2 Offer alternatives for auditory information

1.3 Offer alternatives for visual information

2. Provide options for language, mathematical expressions, and symbols

$2.1 \quad$ Clarify vocabulary and symbols

2.2 Clarify syntax and structure

2.3 Support decoding of text, mathematical notation, and symbols

2.4 Promote understanding across language

$2.5 \quad$ Illustrate through multiple media

3. Provide options for comprehension

3.1 Activate or supply background knowledge

3.2 Highlight patterns, critical features, big ideas, and relationships

3.3 Guide information processing, visualization, and manipulation

3.4 Maximize transfer and generalization

II. Provide Multiple Means for Action and Expression:

Your notes

4. Provide options for physical action

4.1 Vary the methods for response and navigation

4.2 Optimize access to tools and assistive technologies

5. Provide options for expression and communication

5.1 Use multiple media for communication

5.2 Use multiple tools for construction and composition

5.3 Build fluencies with graduated levels of support for practice and per-

formance 
6. Provide options for executive functions

6.1 Guide appropriate goal setting

6.2 Support planning and strategy development

6.3 Facilitate managing information and resources

6.4 Enhance capacity for monitoring progress

III. Provide Multiple Means for Engagement:

Your notes

7. Provide options for recruiting interest

7.1 Optimize individual choice and autonomy

7.2 Optimize relevance, value, and authenticity

7.3 Minimize threats and distractions

8. Provide options for sustaining effort and persistence

8.1 Heighten salience of goals and objectives

8.2 Vary demands and resources to optimize challenge

8.3 Foster collaboration and community

8.4 Increase mastery-oriented feedback

9. Provide options for self-regulation

9.1 Promote expectations and beliefs that optimize motivation

9.2 Facilitate personal coping skills and strategies

9.3 Develop self-assessment and reflection

(C) CAST 2011

\section{Appendix C}

\begin{tabular}{|c|c|c|c|}
\hline Objective & 0 Point & 1 Point & 2 Point \\
\hline Representation & $\begin{array}{l}\text { No clear description } \\
\text { of modifying } \\
\text { materials to provide } \\
\text { equal access to all } \\
\text { students }\end{array}$ & $\begin{array}{l}\text { Discusses one or two } \\
\text { modifications of } \\
\text { materials to provide } \\
\text { equal access, but needs } \\
\text { to be explained } \\
\text { more in depth }\end{array}$ & $\begin{array}{l}\text { Discusses three or } \\
\text { more modifications } \\
\text { of materials to } \\
\text { provide equal access } \\
\text { to all students, gives } \\
\text { clear and precise } \\
\text { explanations }\end{array}$ \\
\hline Expression & $\begin{array}{l}\text { No clear description } \\
\text { of providing } \\
\text { alternative } \\
\text { communication } \\
\text { methods }\end{array}$ & $\begin{array}{l}\text { Discusses at least one } \\
\text { alternative } \\
\text { communication } \\
\text { method, but needs to be } \\
\text { explained more in depth }\end{array}$ & $\begin{array}{l}\text { Discusses two or } \\
\text { more alternative } \\
\text { communication } \\
\text { methods, gives clear } \\
\text { and precise } \\
\text { explanations }\end{array}$ \\
\hline Engagement & $\begin{array}{l}\text { No clear description } \\
\text { of strategies to involve } \\
\text { or engage students } \\
\text { with disabilities }\end{array}$ & $\begin{array}{l}\text { Discusses one or two } \\
\text { strategies to involve } \\
\text { students with } \\
\text { disabilities, but needs } \\
\text { to be explained } \\
\text { more in depth }\end{array}$ & $\begin{array}{l}\text { Discusses three or } \\
\text { more strategies to } \\
\text { involve students with } \\
\text { disabilities, gives } \\
\text { clear and precise } \\
\text { explanations }\end{array}$ \\
\hline
\end{tabular}

Note: Scoring Rubric developed by Spooner, Baker, Harris, Ahlgrim-Delzell, \& Browder 2007. 